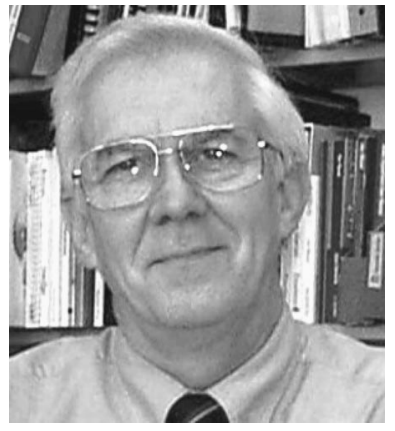

\section{Speed Bumps}

I live on Lullwater Road, one of the prettiest streets in Atlanta. Arguably, it is one of the prettiest streets in America. Druid Hills, the neighborhood where my house resides, was laid out by Frederick Law Olmsted, one of America's best landscape designers whose credits include New York's Central Park. From broad, steep lawns many of the houses overlook the street whose length is two long blocks intersected by a single side street quaintly named The By Way. At the opposite end of Lullwater from our house is the house used in the movie Driving Miss Daisy. Because our lots are quite deep (500 feet or greater), the utility lines are strung through the neighborhood behind our lots. So instead of telephone poles or streetlights on Lullwater, there are large overarching trees. It is a pleasant street to drive on.

Some time ago a few of our newer neighbors were bothered by how fast some cars traveled on our street. Although there has been some increase in the speed of cars over the years, the hills and curves of Lullwater Road make it difficult to travel very fast. Still they wanted the cars to slow down. What if a speeding car hurt some child?

Traffic percolates through Druid Hills from Ponce de Leon, the major street running east from midtown Atlanta, to the area around Emory University and the Centers for Disease Control by way of Lullwater and three parallel streets. Recently, some of the neighbors and DeKalb county planners proposed to slow traffic by installing speed bumps about every hundred yards or so on these streets. A series of meetings took place where these proposals were discussed. If $60 \%$ of the residents on the street agreed, the neighbors would be assessed for the cost and the speed bumps would be installed. Most of the neighborhood, including my wife and I, were strongly opposed to speed bumps. We had raised four children here. With the large back yards and a sense of responsibility, we never found traffic to be a problem. As it turned out the residents of all four streets voted to reject the speed bumps. We were lucky; we had a choice.
Speed bumps are one example of a means of controlling behavior called incapacitation. This is a substitute for another means, accountability, which can be established by having a cop with a radar gun sitting just over the hill near our house. As Edward Tenner points out in an article, "You bought it. Who controls it?" in the June 2003 issue of Technology Review, there are two technologies that are used to control traffic on our streets. One requires cops, clerks, and courts; the other, one road crew to lay two rows of concrete block and then fill the space between them and shape short ramps with asphalt. The second technology is eminently simple, but jarring . . . literally!

Incapacitation is becoming a popular method of control these days. And in many cases you have no choice, no vote. In the fields of computer software, audio and video recording, and electronic devices, the use of incapacitation has increased dramatically in recent years. This might seem to be a fairly benign approach to keeping people honest. Unfortunately, the consequences may be to cripple those who are involved in innovation, while barely slowing the pirates and hackers as they devise their next strategy to overcome the restrictions intended to incapacitate.

Innovation proceeds not by incredible Einsteinian insights, but rather through annoyance and pride. Many changes occur because something isn't working as well as it should or because a device can be made to do something that the inventors never considered. Tenner gives the example of farmers using the drive axle of a Model $\mathrm{T}$ to power farm equipment. As additional controls are imposed on the programs and devices we buy, the flexibility that users employ to adapt it to their own situations and solve their particular problems will be reduced or eliminated.

It will also discourage discovery. Tinkering has been one of the most fruitful forms of self-education for budding engineers. But the current controls will make it harder to tinker and learn. Consider the consequences if, in earlier times, a wind-up alarm clock were made so that any attempt to open it up and see how it worked would make the clock inoperable and scramble its parts when it was opened.

This growth of incapacitation and tamperproofing of our modern technology might be compared to a transition from speed bumps to slow down traffic to one where all streets are changed into limited access roads. You can use them, but you cannot explore the neighborhood. This trend could slow the development of new technologies. On top of this, some technology companies in the US may use the Digital Millennium Copyright Act to quash any innovation without having to go through the older, more revealing patenting process. At that point these technological speed bumps and limited access roads may become stone walls.
Donald C. O'Shea Editor 